planning the trial ; Mr. D. Neill, of the Biochemistry Laboratory, for the electrolyte and blood urea estimations; Professor J. W. Dundee and Dr. J. A. Fisher for the loan of apparatus; and Merck Sharp \& Dohme Ltd. and Nicholas Laboratories Ltd. for co-operating to produce and supply identical tablets of the two active drugs and the placebo free of charge. We are grateful to our colleagues in the Department of Therapcutics and Pharmacology for help in referring patients, and to Professor O. L. Wade for encotragement and advice. The hyperaemic cream used in connexion with ear oxymetry was Finalgon, supplied by Pfizer Ltd. We wish to acknowledge financial help from the Wellcome Foundation, the Northern Ireland Hospitals Authority, the Royal Victoria Hospital Endowment Fund, and the Medical Research Council.
REFERENCES

Baker, H., and Pegum, J. S. (1963). Brit. med. F., 2, 1473.

Campbell, E. J. M. (1960). Ibid., 1, 457.

- and Howell, J. B. L. (1960). Ibid., 1, 458.

Dorris, R., Olivia. Ju., 2, 630.

Hughes, D. (1963). Brit. F. Dis. Chest., 57, 204.

Kellaway, G. (1959). Lancet, 2, 768.

Little, G. M. (1962). Brit. med. 7., 1, 223.

McNicol, M. W., and Pride, N. B. (1961). Lancet, 1, 906.

Naimark, A., Brodovsky, D. M., and Cherniack, R. M. (1960). Amer. F. Med., 28, 368.

Scadding, J. G. (1963). Brit. med. 7., 2, 1269.

Simpson, T. (1961). Lancet, 1, 54.

\title{
Relation Between Myasthenia Gravis and Thyroid Disease
}

\author{
B. M. SAHAY,* M.B., M.R.C.P. ; L. M. BLENDIS, $\dagger$ M.B., M.R.C.P. ; RAYMOND GREENE, $\ddagger$ M.A., D.M., F.R.C.P.
}

The relation between myasthenia gravis and thyroid disease remains unclarified. The association is thought to be uncommon, and it is generally believed that hyperthyroidism is far more commonly associated with myasthenia gravis than is hypothyroidism. However, no explanation has been offered to account for this difference. The association of myasthenia gravis and hyperthyroidism has been reported by many authors (Rennie, 1908 ; Cohen and King, 1932; Thorner, 1939 ; McEachern and Parnell, 1948 ; Greene, 1949 ; Bartels and Kingsley, 1949 ; Levy et al., 1951 ; Millikan and Haines, 1953 ; Maclean and Wilson, 1954; Silver and Osserman, 1957). Various estimates place the incidence of hyperthyroidism at from 3 to $8 \%$ in cases of myasthenia gravis. On the other hand, very few cases have been reported of the combination of myasthenia gravis and spontaneous myxoedema. Feinberg et al. (1957) reported two such cases, Greene and Artunkal (1958) one, and Storm-Mathisen (1961) two. One case of myasthenia gravis associated with Hashimoto's disease was reported recently by Daly and Jackson (1964).

There are conflicting reports on the effect of the thyroid status on myasthenia gravis. The " see-saw" relationship that is said to exist between hyperthyroidism and myasthenia gravis -myasthenia waning with hyperthyroidism and waxing with the treatment of hyperthyroidism-is supported by some authors (Thorner, 1939 ; McEachern and Parnell, 1948 ; Bartels and Kingsley, 1949 ; Maclean and Wilson, 1954), while others were unable to confirm its universal validity (Kowallis et al., 1942 ; Carson and Keynes, 1942 ; Sheldon and Walker, 1946 ; Millikan and Haines, 1953; Silver and Osserman, 1957). Drachman (1962) reported that the eumetabolic status was optimal for his athyreotic patient with myasthenia gravis and any departure from this in either the hyperthyroid or the hypothyroid range was detrimental. Engel (1961) was unable to demonstrate any improvement in patients with myasthenia gravis who were deliberately made hyperthyroid by the administration of either triiodothyronine or thyroid stimulating hormone (T.S.H.).

We report eight cases of myasthenia gravis associated with thyroid disease in which the nature of thyroid dysfunction

* Registrar, Department of Endocrinology, New End Hospital, London.
t Late House-physician, Department of Endocrinology, New End
Hospital, London. Present address: Hammersmith Hospital,
London.
$\ddagger$ Senior Physician and Medical Director, Department of Endocrinology, ¥ Senior Physician and Medical
New End Hospital, London. has been established. Of these, five were hypothyroid and three hyperthyroid.

\section{Methods and Materials}

This series extends over a period of 20 years and includes 260 cases of myasthenia gravis and over 12,000 cases of thyroid disease. All the patients with myasthenia gravis who survived the first five years of this period were examined by one of us (R. G.), who also examined the majority of patients with thyroid disease. In the past thyroid function tests were performed only in those cases of myasthenia gravis in which thyroid dysfunction was suspected; but in the last two years they were performed in all cases. These tests included the determination of the serum protein-bound iodine (Bird and Jackson, 1962), the total 48-hour urinary excretion of an orally administered dose of ${ }^{131} \mathrm{I}$, the thyroid index " $\mathrm{T}$ " (Russell Fraser, 1956), the immediate thyroidal uptake of ${ }^{131}$ I (Farran, 1958), the uptake of ${ }^{131}$ I-labelled triiodothyronine by the red blood cells (Hamolsky et al., 1959), hereinafter referred to as the T3 test, the serum cholesterol, and the B.M.R. Not all these tests were performed in every case.

All patients with myasthenia gravis and patients with thyroid disease in whom myasthenia gravis was suspected were subjected to the diagnostic tests for myasthenia gravis. These included response to intravenous injection of edrophonium chloride (Tensilon) or an intramuscular injection of neostigmine (Prostigmin), ergometry (Greene et al., 1961), the decamethonium-Tensilon test (Churchill-Davidson and Richardson, 1952), and electromyography.

\section{Case 1}

A man aged 56 was referred from another hospital in March 1963. Diabetes mellitus had been detected in 1961 and after his admission to this hospital was stabilized by 76 units of insulin zinc suspension (I.Z.S.). There was a six-month history of progressively increasing weakness and undue fatigability of the ocular, bulbar, facial, and limb muscles. On examination he had a myasthenic facies and smile, bilateral ptosis, generalized limb-muscle weakness, and fatigability. The skin was cool, dry, and rough. The deep tendon reflexes showed delayed relaxation in the upper limbs.

Investigations.-The total 48-hour ${ }^{131}$ I urinary excretion was $65 \%$ and the thyroid index 1.4. The immediate neck uptake of 
${ }^{131}$ I (" $S$ " value) was minus 0.09 and it failed to rise on T.S.H. The ergometry was diagnostic of myasthenia gravis. Responsiveness to Tensilon was moderately good. The electromyogram gave a record typical of myasthenia gravis. An anterior mediastinal pneumogram showed a thymus of normal size.

A therapeutic trial with triiodothyronine 20 ug. t.d.s. produced no clinical or ergometric evidence of a change in the myasthenic state although he became euthyroid clinically and the result of the T3 test was $20.2 \%$. Thymectomy performed in May 1963 produced a moderate improvement in the myasthenic symptoms. Histology of the thymus showed the changes of myasthenia gravis.

\section{Case 2}

A woman aged 52 complained in November 1962 of an eightmonth history of lethargy, easy fatigability, a husky voice, a coarse and dry skin, a puffy face, slightly drooping upper eyelids, and occasional difficulty in chewing. On examination the skin was cool, dry, and rough. The hair was coarse and dry. There was a very mild bilateral ptosis. The pulse rate was 60 per minute.

Investigations.-The total 48-hour ${ }^{131}$ I urinary excretion was $56 \%$ and the thyroid index 2.8 , both within the hypothyroid range.

A diagnosis of mild hypothyroidism was made and treatment begun with L-thyroxine $0.3 \mathrm{mg}$. daily. In March 1963 she was admitted with a two-week history of progressively increasing dysphagia, regurgitation of fluids, slurred and nasal speech, bilateral drooping of upper eyelids, and moderately severe weakness of proximal limb muscles. On examination she showed a typical myasthenic facies and smile, bilateral ptosis, severe weakness of facial, bulbar, and proximal limb muscles, and undue fatigability. There was an excellent response to Tensilon. An anterior mediastinal pneumogram showed the presence of a thymic tumour. Thymectomy performed in May 1963 produced a moderately good improvement in myasthenic symptoms. Histology of the thymus showed a thymo-lympho-epithelioma. She continued to need treatment with thyroxine and pyridostigmine bromide (Mestinon).

\section{Case 3}

A woman aged 53 complained in 1942 of a two-year history of diplopia, weakness of the bulbar and limb muscles, and undue fatigability. On examination she had a myasthenic facies and smile. There was moderate weakness and fatigability of the bulbar and limb muscles. The responsiveness to neostigmine was good. The B.M.R. was minus $14 \%$. Thymectomy performed in 1942 produced an excellent remission in the myasthenic symptoms. Histology of the thymus revealed an atrophic gland. She gradually reduced the dose of neostigmine over the next 10 years after thymectomy, and in 1952 was symptomless without any neostigmine. She returned in 1956 with a one-year history of increasing sensitivity to cold, lethargy, sluggishness, puffy face, and a deep voice. On examination her face was puffy, her skin cool, dry, and rough, and her pulse rate 66 per minute. She had a small diffuse goitre. There was no evidence of myasthenia gravis.

Investigations. - The total 48-hour ${ }^{131}$ I urinary excretion was $81 \%$ and the thyroid index 2.9. The B.M.R. was minus $34 \%$, minus $23 \%$, and minus $33 \%$ on three separate determinations.

A diagnosis of myxoedema was made and treatment with L-thyroxine was started. She continued to need a dose of $0.5 \mathrm{mg}$. daily te remain euthyroid.

\section{Case 4}

An Egyptian woman aged 52 complained in July 1961 of a seven-year history of progressively increasing general muscular weakness and undue fatigability. Her face was puffy, the skin cool, dry, and rough, and her voice deep. The tendon reflexes were sluggish.

Investigations.-Responsiveness to. Tensilon was very good. Ergometry was diagnostic of myasthenia gravis. The serum P.B..$^{127} \mathrm{I}$ was $2.2 \mu \mathrm{g} . / 100 \mathrm{ml}$. Thymectomy performed in August 1961 produced a very good and sustained improvement in the myasthenic symptoms. Histology of the thymus showed changes of myasthenia gravis. She was discharged taking $\mathrm{L}$-thyroxine $0.2 \mathrm{mg}$. daily, which relieved her symptoms due to hypothyroidism without any effect on the myasthenic status.

\section{Case 5}

This case was previously reported by Greene and Artunkal (1958). A Turkish woman aged 30 developed ptosis of the right eye in March 1955. In December 1955 she began to fall on the stairs. At first she could rise by her own efforts but later had to be helped. In 1956 a diagnosis of myasthenia gravis was made and treatment with neostigmine produced very good results. A goitre was noticed at this time and exophthalmos developed; the 24-hour neck uptake of ${ }^{131} \mathrm{I}$ was found to be $64 \%$. After an eight-day course of triiodothyronine the 24 -hour neck uptake of ${ }^{131} \mathrm{I}$ was still $63 \%$, but she noticed that she was very much stronger while on triiodothyronine and was able to give up neostigmine completely. On cessation of triiodothyronine administration she became very weak and needed neostigmine again. Some time later thyroid extract was prescribed and neostigmine could be abandoned without any return of myasthenic symptoms. Finally she settled to a treatment consisting of triiodothyronine and occasional Mestinon.

She was seen by one of us (R. G.) in 1957, at which time she had ptosis of the left upper eyelid, bilateral exophthalmos, and complete palsy of upward and lateral movements of the right eye and the medial movement of the left eye. The upward movement of the left eye was weak. The thyroid gland had become impalpable and she appeared to be in normal thyroid balance. Thyroid administration was discontinued and her myasthenic symptoms became worse.

Investigations, after a suitable interval, showed a serum cholesterol of $292 \mathrm{mg} . / 100 \mathrm{ml}$. The total 48 -hour urinary excretion of ${ }^{131} \mathrm{I}$ was $52 \%$ and the thyroid index 2.9 . The responsiveness to Tensilon was excellent, ptosis and ophthalmoplegia disappearing. The decamethonium-Tensilon test was indicative of myasthenia gravis.

All treatment was stopped for a day and she became completely paralysed except for the respiratory muscles. Complete relief was obtained with Mestinon $60 \mathrm{mg}$. t.d.s. Mestinon was later stopped and treatment with triiodothyronine substituted. She could tolerate a large dose of triiodothyronine and almost all her symptoms of myasthenia gravis were completely relieved by a dose of $50 \mu \mathrm{g}$ t.d.s. alone. Mestinon $60 \mathrm{mg}$. t.d.s. was added and she showed complete remission of her symptoms and clinical signs.

The diagnosis of this case is uncertain. The change from undoubted thyrotoxicosis to a condition on the borderline of the hypothyroid range suggests that she suffered originally from autoimmune thyroiditis. The recession of the goitre supports this suggestion. She remained extremely well, taking triiodothyronine regularly and an occasional tablet of Mestinon. Attempts to substitute a placebo for the former have been frustrated by the fact that she is a pharmacist, but continued careful observation by Professor Artunkal has convinced him that the need for triiodothyronine is a real one.

\section{Case 6}

A woman aged 28. A diagnosis of thyrotoxicosis and myasthenia gravis was made at another hospital. The two-hour neck uptake of ${ }^{131} \mathrm{I}$ was $76 \%$, and serum P.B. ${ }^{131} \mathrm{I}$ at 48 hours was $1.9 \% / 1$. of plasma. There was a good improvement in the myasthenic symptoms on intramuscular neostigmine. She was treated with oral neostigmine and carbimazole $20 \mathrm{mg}$. t.d.s.

Two months later she was seen here when clinically she was still both thyrotoxic and myasthenic. Ergometry confirmed the diagnosis of myasthenia gravis. Thymectomy produced considerable improve-ment in the symptoms of myasthenia gravis. Histology of the thymus showed the changes of myasthenia gravis. Carbimazole therapy was continued until the following year, when a partial thyroidectomy was performed. Histology of the thyroid gland showed the changes of Graves's disease. Soon after thyroidectomy there was a further improvement in the myasthenic symptoms, especially of bilateral ptosis and facial weakness.

\section{Case 7}

This case was previously reported by Greene (1949). A woman aged 27 noticed in February 1947 the onset of diplopia, which became worse towards the evening. In April she developed bilateral exophthalmos and patchy pigmentation of the skin. She began to lose weight rapidly and soon after developed all the classical symptoms and signs of thyrotoxicosis. Treatment with thiouracil 
was started in May. She was seen by one of us (R. G.) in October 1947, at which time she had bilateral exophthalmos, ptosis of the left upper eyelid, myasthenic facies and smile, extreme weakriess of the muscles of the arms and legs, with easy fatigability, persisten tachycardia, warm and sweaty palms, and a diffuse hyperplastic goitre over which a loud bruit could be heard. She had bilateral partial external ophthalmoplegia and patchy pigmentation of the arms and legs. There was an excellent response to an intramuscular injection of neostigmine which produced a very considerable increase in muscle power in all muscle groups except the external recti. It was thought that the external rectus paresis was due to thyrotoxic myopathy.

A partial thyroidectomy was performed in October 1947. Histologically the thyroid gland showed changes typical of Graves's disease. There was an excellent remission in the symptoms of thyrotoxicosis, but the dose of neostigmine had to be increased to two tablets three-hourly from one tablet three times a day. In November 1947 thymectomy was performed. The thymus weighed $18.5 \mathrm{~g}$. Histology of the thymus showed the changes of myasthenia gravis. Soon after thymectomy the dose of neostigmine could be halved. There was a progressive improvement in the myasthenic symptoms and in August 1948 she was taking only four tablets of neostigmine daily and was completely symptom-free except for the external rectus paresis, which later resolved.

An interesting feature of this case was that the vitiligo improved soon after partial thyroidectomy. It later reappeared when she became pregnant, but disappeared again soon after the birth of her child.

\section{Case 8}

A man aged 33 went to another hospital in July 1942 with a six-month history of loss of weight, tachycardia, recurrent episodes of palpitations, diplopia, and drooping of both upper eyelids. On examination he had a diffuse goitre, tachycardia, bilateral ptosis, and partial external rectus paresis on both sides. A clinical diagnosis of thyrotoxicosis was made, being confirmed by the determination of the B.M.R. A partial thyroidectomy was performed in July 1942.

He was first seen at this hospital in July 1948 with a six-year history of progressively increasing generalized muscular weakness and undue fatigability. He needed 30 tablets of neostigmine a day for an adequate scale of activity. On examination he showed a typical myasthenic facies and smile, bilateral ptosis, partial external ophthalmoplegia, and severe weakness of proximal limb muscles. The response to intramuscular neostigmine was good. On clinical assessment he was euthyroid and there was no goitre. Thymectomy performed in July 1948 produced only a mild improvement in the myasthenic symptoms. He was admitted in September 1963 for reassessment. The severity of myasthenic symptoms had varied considerably over the 15 years since the thymectomy. At the time of writing he was taking six Mestinon and six ephedrine tablets a day, which gave him a fair scale of activity. He appeared to be euthyroid on clinical assessment. His serum P.B. ${ }^{127} \mathrm{I}$ was $4.1 \mu \mathrm{g}$./ $100 \mathrm{ml}$., the total 48 -hour ${ }^{131} \mathrm{I}$ urinary excretion was $47 \%$, and the thyroid index 3.9. In this case correction of the thyrotoxicosis has had no effect on his myasthenic symptoms.

\section{Discussion}

Interest in the relation between myasthenia gravis and thyroid disease has been evident since Rennie (1908) described a case of exophthalmic goitre and myasthenia gravis. This relation was strengthened by the recognition of histological similarities of the involved muscle tissue in myasthenia gravis and thyrotoxicosis (Weigert and Laquer, 1901 ; Dudgeon and Urquhart, 1926 ; Cohen and King, 1932). At necropsy Giordano and Haymond (1944) and Ringertz (1951) examined the thyroid gland in their cases of myasthenia gravis and reported that the histological changes were consistent with previous thyroid hyperplasia associated with thyrotoxicosis. Lymphoid follicles with germinal centres are seen in the thyroid gland in Hashimoto's disease (Greene, 1950) and also in the thymus of myasthenia gravis (Burnet, 1962), both of which are now believed to be autoimmune diseases (Roitt et al., 1956 ; Burnet,
1962). However, the presence of both these diseases in the same person has only once been previously reported (Daly and Jackson, 1964).

McEachern and Parnell (1948) quote Eaton from the Mayo Clinic, who gave a $6 \%$ incidence of hyperthyroidism in his series of cases of myasthenia gravis. But the diagnosis was confirmed by the determination of the B.M.R. alone, a method of diagnosis which is often unreliable. Millikan and Haines (1953) gave a $5 \%$ incidence of hyperthyroidism in their cases of myasthenia gravis. Silver and Osserman (1.957) studied the thyroid function by radioiodine tests in 57 cases of myasthenia gravis: 52 were euthyroid and five were found to be hyperthyroid.

Although the association of myasthenia gravis and hyperthyroidism is well known, its association with hypothyroidism is alleged to be extremely rare. In none of the aforementioned series was a single case of hypothyroidism reported. Feinberg et al. (1957) reported three such cases, in none of which myxoedema developed after a subtotal thyroidectomy was performed for primary thyrotoxicosis and which therefore is not a valid example of this association. Storm-Mathisen (1961) reports her studies on 90 cases of myasthenia gravis seen at the University Hospital, Oslo. Two of these cases had associated hypothyroidism, but unfortunately she gives no details of the clinical picture or laboratory investigations to support the diagnosis of myxoedema. Garvey (1930) found low basal metabolic rates in two cases of myasthenia gravis and suggested that this might be a feature of the disease itself. This assumption was refuted by Kowallis et al. (1942), who determined the B.M.R. in 40 patients with myasthenia gravis and found it to be in the normal range. At the New End Hospital the B.M.R. is not assessed as a routine, and therefore we cannot give any further information about this.

In this series of 260 cases of myasthenia gravis there were eight proved cases of associated thyroid disease. It may be that there were cases in which thyroid disease was present, either not suspected or not sufficiently investigated for inclusion in this series. It must be emphasized that hypothyroidism is more likely than thyrotoxicosis to be missed clinically.

Of these eight cases, five were hypothyroid and three hyperthyroid. This incidence of hypothyroidism is contrary to the published reports of the relation between thyroid disease and myasthenia gravis. The "see-saw" relation was evident only in Case 6, as the treatment of thyrotoxicosis both with antithyroid drugs and later with a partial thyroidectomy produced distinct worsening of myasthenia. None of the other cases shows evidence in favour of a "see-saw" relationship.

Myasthenia gravis is thought to be an autoimmune disease, but we did not find in this series a proved case of Hashimoto's disease and myasthenia gravis.

\section{Summary}

It appears from this series of 260 cases of myasthenia gravis that the present impression that hyperthyroidism is an associated disease needs further investigation. In our series hypothyroidism was more frequent. The often-stated "see-saw" relationship between thyroid status and myasthenic symptoms is unsupported by the evidence. It is possible that the relation between the two diseases is a chance one, but the generally accepted view that Hashimoto's disease and myasthenia gravis are both due to autoimmune reactions casts some doubt on this. Moreover, it has recently been suggested that not only spontaneous myxoedema, but thyrotoxicosis itself, may be autoimmune diseases, and that thyrotoxicosis may be due to the presence of a "long-acting thyroid stimulator" which may be itself an antibody. Such speculations demand a more careful immunological investigation of myasthenia gravis than has hitherto been made. 
We wish to thank Mr. J. E. Piercy, Mr. M. J. Lange, and Dr. A. Stuart Mason for their kind permission to study patients under their care.

\section{REFERENCES}

Bartels, E. C., and Kingsley, J. W., jun. (1949). Lahey Clin. Bull., 6, 101.

Bird, R., and Jackson, D. J. (1962). Clin. Chem., 8, 389.

Burnet, M. (1962). Proc. roy. Soc. Med., 55, 619.

Carson, J., and Keynes, G. L. (1942). Ibid., 36, 140.

Churchill-Davidson, H. C., and Richardson, A. T. (1952). Ibid., 45, 179.

Cohen, S. J., and King, F. H. (1932). Arch. Neurol. Psychiat. (Chic.), $28,1338$.

Daly, J. J., and Jackson, E. (1964). Brit. med. f., 1, 748

Drachman, D. B. (1962). New Engl. F. Med., 266, 330.

Dudgeon, L. S., and Urquhart, A. L. (1926). Brain, 49, 182.

Engel, A. G. (1961). Arch. Neurol. (Chic.), 4, 663.

Farran, H. E. A. (1958). Brit. med. F., 2, 1060.

Feinberg, W. D., Underdahl, L. O., and Eaton, L. M. (1957). Proc. Mayo Clin., 32, 299.

Fraser, R. (1956). Lancet, 2, 581.

Garvey, J. L. (1930). Ann. intern. Med., 3, 917.
Giordano, A. S., and Haymond, J. L. (1944). Amer. F. clin. Path., 14, 253.

Greene, R. (1949). Proc. roy. Soc. Med., 42, 263.

(1950). F. Endocr., 7, 1 .

and Artunkal, S. (1958). Türk. Tip. Cem. Mec., 24, 199.

- Rideout, D. F., and Shaw, M. L. (1961). Lancet, 2, 281.

Hamolsky, M. W. "Golodetz, A., and Freedberg, A. S. (1959). F. clin. Endocr., 19, 103.

Kowallis, G. F., Haines, S. F., and Pemberton, J. de J. (1941). Proc. Mayo Clin., 16, 545.

Levy, G., Meadows, W. R., and Gunnar, R. M. (1951). Ann. intern Med., 35, 134.

McEachern, D., and Parnell, J. L. (1948). f. clin. Endocr., 8, 842.

Maclean, B., and Wilson, J. A. C. (1954). Lancet, 1, 950.

Millikan, C. H., and Haines, S. F. (1953). Arch. intern. Med., 92, 5.

Rennie, G. E. (1908). Rev. Neurol. Psychiat., 6, 229.

Ringertz, N. (1951). Acta path. microbiol. scand., $29,9$.

Roitt, I. M., Doniach, D., Campbell, P. N., and Hudson, R. V. (1956) Lancet, 2, 820 .

Sheldon, J. H., and Walker, R. M. (1946). Ibid., 1, 342.

Silver, S., and Osserman, K. E. (1957). F. Mt Sinai Hosp., 24, 1214.

Storm-Mathisen, A. (1961). Myasthenia Gravis. Aschehoug, Oslo.

Thorner, M. W. (1939). Arch. intern. Med., 64, 330.

Weigert and Laquer (1901). Neurol. Cent., 20, 594.

\title{
Detection of Bacteriuria by a Modification of the Nitrite Test
}

\author{
J. DOUGLAS SLEIGH,* M.B., CH.B., M.C.PATH.
}

Brit. med. F., 1965, 1, 765-767

Urinary infections are characterized by periods when bacteria, almost always coliform organisms, multiply in the urine within the urinary tract. When this happens the urine usually contains 100,000 or more bacteria per ml. (significant bacteriuria), whereas lower numbers of organisms are most often contaminants which have entered the urine from the urethra or external genitalia while the specimen was being voided (Kass, 1955). Significant bacteriuria, which may be asymptomatic, seems to be related to active pyelonephritis (MacDonald et al., 1957) and probably to the development and progression of chronic pyelonephritis (Quinn and Kass, 1960). The recognition of significant bacteriuria by enumeration of the bacteria in each millilitre of urine, however, is laborious and expensive, and large-scale surveys to detect patients with asymptomatic bacteriuria would be greatly facilitated by the use of a simple and reliable screening test.

Nitrites, which are easy to detect chemically, are not found in normal urine, and it was Cruickshank and Moyes (1914) who noted that the presence of nitrites in urine was associated with coliform bacteriuria. This nitrite is formed from the nitrate in urine by bacterial action. However, when the nitrite test is applied to specimens of freshly voided urine only about half of those with significant bacteriuria give a positive result. This study was undertaken to see if it was possible to increase the usefulness of the nitrite reaction as a test for bacteriuria.

\section{Materials and Methods}

During this study 1,530 urine specimens were examined. All were mid-stream specimens passed either without preparation or after simple washing of the genital region by the patient. The majority of the urines came from women attending either an antenatal or an infertility clinic, and these specimens reached the laboratory within two hours of being voided. The rest of the specimens were from patients who had consulted their

* Lecturer in Bacteriology, University of Edinburgh. general practitioners, and most, but not all, of them were submitted in special containers which maintain a low temperature during transit (Elliott and Sleigh, 1963). When the specimens of urine reached the laboratory they were either examined at once or refrigerated until the following morning. Every specimen was cultured quantitatively by dropping known volumes of urine, diluted and undiluted, on to the surface of blood-agar plates.

The presence of nitrite in urine was detected by the Ilosvay modification of the Griess test. The reagents used were: solution A, $1.25 \mathrm{~g}$. of sulphanilic acid in $500 \mathrm{ml}$. of $30 \%$ acetic acid; solution $\mathrm{B}, 2.5 \mathrm{~g}$. of $\alpha$-naphthylamine in $500 \mathrm{ml}$. of $30 \%$ acetic acid. Each day equal volumes of solutions A and $\mathrm{B}$ were mixed together and the test was performed by adding $1 \mathrm{ml}$. of the resulting solution to $1 \mathrm{ml}$. of urine. If a red or pink colour developed the test was regarded as positive.

The first part of the investigation concerned 530 urines. All these urines were first examined for nitrites; this initial test was positive in 30 and negative in 500 . Twelve $1-\mathrm{ml}$. aliquots were then taken from each specimen and to six of them two $0.02-\mathrm{ml}$. drops of a $5 \%$ solution of potassium nitrate in distilled water were added. The samples were then placed in an incubator at $37^{\circ} \mathrm{C}$. for six hours. At hourly intervals two samples, one with and one without added nitrate, were tested for the presence of nitrites.

The second part of the investigation dealt with 1,000 urines which were not examined for nitrites initially. The ability of a modified nitrite test to detect significant bacteriuria in these specimens was compared with that of the triphenyl tetrazolium chloride (T.T.C.) test of Simmons and Williams (1962). In the modified test which was developed from the results of the first part of the study $1 \mathrm{ml}$. of urine, with added nitrate, was incubated undisturbed in a water-bath at $37^{\circ} \mathrm{C}$. for four hours before being tested for nitrites. The T.T.C. test was carried out by the method of Simmons and Williams (1962) but using $1 \mathrm{ml}$. of urine and $0.25 \mathrm{ml}$. of the working solution of T.T.C. This test was read after four hours' incubation in 